\title{
Planteamientos sociopolíticos de la educación en el pensamiento filosófico griego antiguo: Sócrates, Platón y Aristóteles
}

\section{Socio-political approaches of education in old greek philosophical thought: Socrates, Plato and Aristotle}

Paulina Morales Hidalgo

José Ángel Bermúdez García

Jean Carlos García Zacarías

Pontificia Universidad Católica del Ecuador, Ecuador

Autor para correspondencia: pmorales048@puce.edu.ec, bjoseangel@yahoo.es, jgarcia493@puce.edu.ec

Fecha de recepción: 30 de Agosto 2017 - Fecha de aceptación: 15 de Enero de 2018

Resumen: La Grecia Clásica del siglo v a.C. vivía un momento particular de crisis que sustituyó el régimen tradicional aristocrático por el democrático. Tal situación dio origen a una educación nueva y de mayor complejidad. En este contexto, aparecieron con su estela de sabiduría los mejores pensadores que brillando por sus ideas filosóficas, éticas, políticas y educativas, cuyos planteamientos fundamentales constituyen los primeros postulados sociopolíticos de la educación y de mayor influencia para la cultura occidental. Por este motivo, este ensayo tiene como objetivo fundamental analizar los principales planteamientos sociopolíticos de la educación en el pensamiento filosófico griego antiguo, expuesto por sus tres más grandes representantes: Sócrates, Platón y Aristóteles. Del análisis emergió que (1) los planteamientos sociopolíticos de la educación se enmarcan en los principales interrogantes de orden antropológico, filosófico y ético; (2) le asignaron a la educación la tarea última de la existencia de la comunidad y de la individualidad humana; (3) la educación debía formar al "hombre griego", al hombre libre; (4) la educación política deriva de la antropología y se realiza en la vida ética que se vierte en vida dentro de la polis; (5) la riqueza de los postulados sociopolíticos de la educación griega encuentra su fecundidad en su valor humanístico, que es distinta en estos filósofos.

Palabras claves: educación; política; sociedad; estado; ética; moral; filosofía; antropología

Abstract: The Classical Greece of the fifth century a.C. lived a particular moment of crisis that replaced the traditional aristocratic regime by the democratic. This situation gave rise to a new and more complex education. In this context, the best thinkers who shone through their philosophical, ethical, political and educational ideas appeared with their wake of wisdom; whose approaches constitute a set of socio-political postulates of education and of greater influence for Western culture. For this reason, this dissertation essay aims to analyze the main sociopolitical approaches to education in ancient Greek philosophical thought, exposed by its three greatest representatives: Socrates, Plato and Aristotle. From the analysis emerged that (1) the sociopolitical approaches of education are framed in the main questions of anthropological, philosophical and ethical order of the time; (2) they assigned to education the ultimate task of the existence of community and human 
individuality; (3) education was to form the "Greek man", the free man; (4) political education derives from anthropology and is realized in the ethical life that is poured into life within the polis; (5) the wealth of the sociopolitical postulates of Greek education finds its fecundity in its humanistic value, which is distinctive in these Greek philosophers.

Key Words: education; politics; society; state; ethics; morals; philosophy; anthropology

\section{Introducción}

Desde tiempos inmemoriales, la sociedad ha instituido la educación como un mecanismo de control que permite que cada uno de sus miembros le sea trasmitido un conjunto de normas y valores que aseguran su supervivencia; por eso no es de extrañar que, cuando algo anda mal en la sociedad o está entra en crisis, todas las miradas se dirijan hacia la institucionalidad de la educación.

Por este motivo, no es casual que el origen del pensamiento sobre la educación, en paralelo con el pensamiento filosófico, ético y político, se diera en la Grecia antigua. El surgimiento de las primeras reflexiones sobre la educación se han de entender en un contexto particular, de crisis, en el cual, según algunos críticos:

Los griegos del siglo $\mathrm{V}$ asistieron al resquebrajamiento de la cosmovisión tradicional bajo el peso de la incipiente interpretación científica del mundo; a la crítica de la religión mitológica promovida por lo primeros filósofos; y a la relativización de sus propias costumbres provocadas por el contacto con otros pueblos". (Rodríguez, 2006, p. 216).

La Grecia clásica vive y sufre una gran transformación social y política, pasando a una polis (Estado-Ciudad) rural-agrícola, a una gran potencia económica y política que sustituyó el régimen tradicional aristocrático por el democrático. Todas estas situaciones antes señaladas desembocaron en la perdida de vigencia del modo de vivir tradicional de los griegos. Los sofistas agudizaron dicha crisis ya que éstos propagaron la tesis de la naturaleza como única norma objetiva que ponía en tela de juicio todo código de conducta recibido. Al socavarse las bases que mantenían en pie la existencia cotidiana de la cultura del momento, se empezaron a gestar los primeros pensamientos educativos, que exigían una nueva educación y de mayor complejidad, para una nueva sociedad de mayor complejidad en el orden social y político que exigía, por igual, de la participación de los ciudadanos en los asuntos públicos. Al punto que la palabra "pedagogía", en cuanto es utilizada en nuestros días para referirnos a la teoría de la educación, surgió en la Grecia antigua.

En este contexto, aparecieron con su estela de sabiduría los mejores pensadores, como fueron Sócrates, Platón y Aristóteles. Se constituyeron en los principales representantes del pensamiento educativo griego, aunque no hayan elaborado un tratado sistemático de la educación, como si es el caso de la filosofía, la ética y la política. Aunque su pensamiento educativo no se puede comprender desvinculado de éstas.

Los primeros planteamientos sociopolíticos de la educación y de mayor influencia en el mundo griego, y para la cultura occidental posterior, se encuentran en ésta triada de filósofos. 
Cuando comenzaron a formular las principales interrogantes de orden filosófico y ético como ¿cuál será la vida mejor para el hombre? ¿Cómo vivir una vida plenamente humana y feliz?, estaban marcando el inicio formal de la reflexión educativa. Le estaban asignando a la educación la tarea última de la existencia de la comunidad y de la individualidad humana (Rentería, 2004, p. 96-97). Desde los planteamientos antropológicos y éticos se derivaron los principios sociopolíticos de la educación griega. La educación debía formar al "hombre griego", el cual, tenía que vivir según la virtud (areté) que le es propia por naturaleza, concibiéndose responsablemente como individuo y ciudadanos de la polis. Hombres libres y políticos, en cuanto ciudadanos, que viven en la polís, la ciudad, centro de la cultura; es decir, según Luzuriaga (1959):

La polis es la fuente de todas las normas de la vida válida para el individuo..., que abarca la totalidad de la existencia..., así se convierte la polis en el educador de la juventud; es el lugar de educación cívica y espiritual..., del espíritu democrático y la libertad política propia de la vida ateniense (p. 49).

De este modo, los griegos crearon una educación de eficiencia individual y, simultáneamente, de la convivencia social y política (Gadotti, 2004, p. 16). Es así que los planteamientos educativos de Sócrates, Platón y Aristóteles son, teleológicamente hablando, en consonancia con los filosóficos y éticos, esencialmente políticos.

No es casualidad que nuestra educación también se enmarque dentro de los principios originales y originantes propios de la cultura griega antigua. En ella se encuentran sus pilares esenciales. Para poder comprender los planteamientos educativos contemporáneos es conveniente tener presente los planteamientos educativos griegos presentes en los tres grandes del pensamiento filosófico antiguo ya mencionados. Es importante conocer sus postulados sociopolíticos, a pesar de su antigüedad, siguen más vigentes que nunca, nuestra civilización se entiende desde ellos. El hombre de ayer como de hoy anda en la búsqueda del sentido y las implicaciones de la educación para la su sociedad.

Este ensayo se inscribe en un proceso de fidelidad y avance de la comprensión de los planteamientos sociopolíticos de la educación en el marco del pensamiento filosófico de Sócrates, Platón y Aristóteles. De fidelidad, en primer lugar, porque se quiere profundizar en el análisis de las implicaciones sociopolíticas de la educación griega clásica tal como se encuentra en la fuente. Y de avance, en segundo lugar, porque se quiere continuar animando el proceso de investigación contemporánea que permita a los filósofos e investigadores educativos de la educación encontrar en éstos pensadores antiguos unos aliados y no unos meros objetos de curiosidad para anticuarios, que permita continuar aportando luces a los principales planteamientos sociopolíticos actuales de la educación.

Desde la perspectiva señalada, este ensayo se plantea como objetivo fundamental analizar los principales planteamientos sociopolíticos de la educación, expuesto por los principales representantes del pensamiento filosófico antiguo griego. Para ello el proceso de indagación procura caracterizar los elementos de la educación de los Sofistas y; en el segundo, y fundamental, expone los principales planteamientos sociopolítico y filosóficos de la educación de Sócrates, de Platón y de Aristóteles. 


\section{Metodología}

Para alcanzar los fines que se plantean, la metodología de esta investigación filosófica y educativa está enmarcada como un estudio de naturaleza documental tipo ensayo. En este orden de ideas, "el ensayo tiene como objetivo exponer ideas o principios relacionados con áreas de conocimiento y de la observación del autor, y el mismo puede tener intencionalidad filosófica, científica, social, cultural" (Barrera, 2000, p. 49). Como señala el Manual UPEL (2006), este tipo de investigación permite la revisión crítica del estado del conocimiento y el estudio del desarrollo teórico donde se presentan las conceptualizaciones originales y las perspectivas de los autores del ensayo.

\section{Análisis y Resultados}

\section{(1) Elementos Sociopolíticos de la Educación Griega}

La civilización griega antigua representa un paradigma nuevo de la cultura universal y del desarrollo del pensamiento occidental. Indudablemente, parte de su florecimiento se debe a la importancia que le asignaron a la educación. Para los griegos ella representaba el sentido de todo esfuerzo humano y de la existencia de la sociedad.

La educación representaba el punto de partida, en cuanto precede al individuo y condicionan a la sociedad. De allí, según Gadotti (2004), que la virtud principal de un hombre griego "debía ser la lucha por su libertad. Además, necesitaba ser racional, hablar bien, defender sus derechos, argumentar" (p. 16). Cosa que no observaba en la aparente estabilidad de los pueblos vecino del Oriente como Persia, Asiria, Egipto, la India y China donde no había cualificación del colectivo, tan sólo "en su fondo colectivo podían proporcionar eran tabúes y ritos cíclicos (cuyas modificaciones se prohibían), representaciones esquemáticas dogmáticamente inmodificables (mitos) y tareas colectivas impersonales" (UPEL, 1999, p.17).

De este modo se explica porque la Grecia antigua fue la cuna del pensamiento filosófico, del pensamiento libre y del nacimiento de las incipientes democracias. Solo era posible porque existía la educación. En Grecia reina un panorama social y político totalmente distinto. Gracias a la educación todo estaba hecho para la evolución de la lucidez, de la libertad y la iniciativa creadora donde la vida privada no iba a quedar absorbida por la organización estatal y la dependencia de una administración imperial que interviene en todo y presiona sobre los individuos.

Mientras que, en los pueblos vecinos de Oriente, de cultura arcaica, concentraron todos sus esfuerzos en la guerra y el autoritarismo, por el contrario, la cultura griega, más adelantada, por su avanzado y moderno pensamiento educativo, con sus matices, en especial Atenas "llego a un estado superior, el de la vida política y democrática" (Luzuriaga, 1959, p. 49).

La educación griega destacó como una educación esencialmente política, por su carácter humano y cívico. El carácter eminentemente político de la educación griega descansa, para su época, según Rentería (2004), "en la nueva concepción de la posición del individuo en la sociedad, enfatizando especialmente en su dimensión individual como principio humanístico; así 
la educación significó el establecimiento en el hombre de su humanidad" (p. 97). La educación política deriva de la antropología, planteamientos que son distintos, como veremos más adelante, a la hora de concebir la educación y sus implicaciones sociopolíticas, de manera especial en Platón y Aristóteles.

De la preocupación antropológica en el descubrimiento del valor humano, del hombre en sí, de su personalidad se constituye para los griegos el fundamento de planteamientos educativos. La preocupación era la educación del hombre integral, esto es según Luzuriaga (1959), "la consideración de la educación humana en su integridad: física, intelectual, ética y estética" ( $p$. 43). De este modo realizaron a través de los planteamientos educativos como teoría sociopolítica la síntesis entre educación y cultura, dando así un valor agregado al arte, a la literatura, a las ciencias y a la filosofía. La tarea de la educación griega es la formación del hombre integral en cuanto formación del cuerpo por la gimnasia (educación física), en la de la mente por las filosofías y las ciencias (educación intelectual), en la moral y la política (educación ética y política) y, finalmente, formación de los sentimientos por la música y por las artes (educación estética). Estos planteamientos teóricos del humanismo educativo caracterizan la riqueza del pensamiento pedagógico griego, en especial el ateniense, donde "las mayores disputas no eran físicas sino intelectuales, se buscaba el conocimiento de la verdad, de lo bello y del bien" (Gadotti, 2004, p. 18).

Todas estas realizaciones educativas de la Grecia del siglo V a.C., propios de la cultura ateniense, es lo que llama Luzuriaga (1959), "la educación nueva" (p. 51), dio paso a una nueva clase social, una democracia más extensa, mayor poder político-militar (liberación frente a Persia) y una cultura con un sentido cada vez más intelectual que devino en una educación de carácter más elevado, que de manera especial se experimentó en la enseñanza superior a través de la educación de la juventud; debido a que "la mayor complejidad de la vida política y social hizo necesaria una mayor preparación para ésta" (Luzuriaga, 1959, p. 51). Tales realizaciones culturales de la educación griega clásica dejan ver las implicaciones que tienen para las generaciones humanas posteriores hasta la nuestra, la cual gravita en muchas de sus reflexiones sobre los postulados educativos señalados. De allí, la importancia que tiene conocer las principales ideas sociopolíticas griegas desarrollados por los más destacados representantes que marcaron el devenir de la cultura occidental.

\section{(2) Principales Planteamientos Sociopolítico y Filosóficos de la Educación Griega}

Los planteamientos sociopolíticos de la educación de la Grecia clásica han tenido una enorme energía procreadora. Periódicamente, la civilización occidental ha vuelto a reflexionar sobre ellos, como ocurrió en el Renacimiento y en la Ilustración y como ocurre en parte en nuestros días. Podemos señalar que los postulados sociopolíticos de la educación griega encuentran su fecundidad en su valor humanístico, por la afirmación de la libertad responsable de los ciudadanos de la polís en medio de las variadas circunstancias políticas. Claro está, que tales planeamientos varían en razón de la concepción de hombre sobre la que se propone una visión de Estado y sociedad, de la cual la educación es garantía. De allí la importancia de conocer a esta triada de filósofos por la densidad de sus propuestas y el significado que han tenido para nuestra cultura.

\section{(3) Los Sofistas, educación para líderes políticos}


No podemos comprender los planeamientos sociopolíticos de la educación griega, en especial los socráticos, sin antes hacer mención de los postulados, en parte coincidente y en parte divergente, de los Sofístas. En realidad, son los primeros educadores profesionales. Según Luzuriaga (1959), "los Sofistas desarrollan su actividad docente como profesores ambulantes en la segunda mitad del siglo $\mathrm{V}$ a. de $\mathrm{C}$. en el momento de la gran transformación social y política de Atenas" (p. 55), la cual exigía una transformación política de la sociedad, que de fondo conllevaría a una transformación educativa, es decir, según Gajate (1999):

los ciudadanos reclaman ahora un puesto de pleno derecho en el gobierno de la nueva sociedad ateniense; pues consideran que ya no es la herencia el valor determinante ni el único que da derecho a participar en la vida pública, sino que ahora el derecho se abre a todos los ciudadanos" (p. 9).

Surge un nuevo paradigma político, que frente al areté de la nobleza surge el areté de la política, la cual exige la formación de nuevos cuadros gobernantes de la polis de entre los hombres libres. La transformación política se dio de la mano con la educativa ya que "esto a su vez exigía una preparación, una educación más alta, más intelectual que la tradicional de la música y la gimnasia” (Luzuriaga, 1959, p. 55).

En este orden de ideas, la mayor complejidad de la vida política y social griega hizo necesaria una mayor preparación para ésta. Los Sofistas propusieron una renovación educativa más elevada de la educación de la juventud que proporcionara la instrucción que necesitaba el hombre político no sólo en oratoria sino también en ciencia. Los postulados sociopolíticos de los sofistas, enmarcados en el humanismo ateniense, perseguían la educación para la vida pública, la formación del político y del orador. El ciudadano que de hecho quería tener una presencia relevante en la vida de la polis, necesitaba prepararse, para librar la batalla en la plaza pública, en la asamblea, en los tribunales, para discutir las leyes. Para ello, se requiere de un saber que se exprese a través del discurso y de la elocuencia.

Por consiguiente, establecen la profesión docente, aunque, sin embargo, fue criticada por Sócrates, Platón y Aristóteles, que los calificaban peyorativamente con el término de Sofistas, según Fischl (2002):

a un tendero que trafica, suciamente a menudo, con la sabiduría, a un alcahuete de ella, a un cazador que va tras los jóvenes ricos para sacarles dinero, a un charlatán que no le importa un bledo la sabiduría, sino que con ella engaña trampea y seduce (p. 54).

A pesar de la calificación despectiva que les da la historia, por prescindir de toda objetividad al acomodar sus enseñanzas a sus deseos y triunfos personales, es decir, sacrificaban la veracidad a la subjetividad. Destacan en sus postulados sociopolíticos de la educación por: (a) acentuar el valor de lo humano, del hombre, más concretamente del individuo en la educación; (b) la educación como medio para el desarrollo de las capacidades del hombre para el ejercicio del gobierno si se está debidamente preparado; y, (c) crearon la educación intelectual y científica de carácter superior que respondiera a las necesidades de una sociedad más evolucionada social y políticamente de carácter democrático. 


\section{(4) Sócrates, intelectualismo moral:}

Encontramos en él puntos de convergencia y divergencia con los sofistas, en lo que respecta a los planteamientos sociopolíticos de la educación. Con ellos insistía en valor del hombre, de la vida personal, estaba inconforme con el concepto de educación tradicional ateniense sometida a la influencia excesiva del Estado; además, coincidía como los sofistas en la virtud, la areté en cuanto capacidad propia de todo hombre y no sólo de la aristocracia, pues era comunicable y enseñable.

Pero las diferencias de Sócrates son aún más profundas y vinculantes para el hombre ateniense. En cuanto que la educación pierde el carácter práctico de aprovechamiento personal, indiferente a la moralidad y la objetividad, para él, el educador por excelencia, la educación adquiere un sentido nuevo, el moral, de preocupación por la vida ética, la cual deriva, no de la utilización de la enseñanza para imponer las ideas o para servir a fines egoístas, sino de la búsqueda de la verdad.

Las implicaciones políticas de su propuesta filosófica para el campo educativo corresponden al dominio de la moral, de la ética. Cómo señala muy bien Luzuriaga (1959), "el fin último de la educación era para Sócrates la virtud, el bien, y no el Estado como lo era para la antigua educación, ni el provecho individual como para los sofistas, sino la personalidad moral" (p. 59). Ahora bien, el fin social de la educación, en cuanto que el hombre es un ser teleológicamente orientado a la virtud, está en la formación moral y ética del ciudadano. El hombre está teleológicamente hecho para la ética, "esta capacidad recibía el nombre genérico de virtud o excelencia (areté), y era interpretada por Sócrates al modo de saber técnico... La virtud se entendía como una dimensión de lucidez que permitía al hombre virtuoso acercarse a la conducta adecuada" (Rodríguez, 2006, p. 217).

Podemos decir, en el contexto de crisis y relativismo moral que gestaron los Sofistas, que la ética nació de la mano de Sócrates con la intención de dar una respuesta, no sólo filosófica, sino también educativa, a los planteamientos profundos sobre la responsabilidad de la existencia y las acciones de los hombres que conviven libremente en la polis. La excelencia moral es la máxima del hombre, la felicidad. El que obra bien vive feliz. Encuentra el fundamento de la praxis ética en lo que se ha llamado el intelectualismo moral, es decir, "sabiendo qué es lo bueno y lo justo se puede obrar bien y justamente. El conocimiento de ello permite al hombre llevarlo a la práctica en la vida social, mientras que su ignorancia le impide obrar conforme a ellos" (Gajate, 1999, p. 15). En este sentido el planteamiento pedagógico y educativo socrático es el intelectualismo, unilateral.

\section{(5) Platón, educación para el Estado y la sociedad:}

Siguiendo de cerca a su maestro, predominan las ideas éticas, la preocupación por la justicia. El fin político de la educación es la formación del hombre moral, y el medio para ello es la educación del Estado, en cuanto este representa la idea de justicia. El Estado no es, pues, un fin en sí mismo, sino un medio para realizar la justicia y la educación conforme a ella.

Para entender el planteamiento sociopolítico de la educación platónica es preciso que describamos qué entiende por Estado. Éste es para Platón producto de su concepción antropológica (Larroyo, 1991). El Estado y la sociedad son un producto de la imagen y semejanza del alma del hombre, como un todo compuesto de tres partes. A las partes humana 
corresponden las funciones básicas de la polis. El Estado no es ninguna creación artificial, la vida social es esencial al hombre. De la teoría de la naturaleza del alma humana desprende su tesis del Estado, de sociedad y de educación.

El Estado, al igual que el alma humana, es un compuesto de tres partes o estamentos esenciales. Estas partes son los tres estamentos que reconoce Paltón: "el pueblo - compuesto de comerciantes, industriales y agricultores-, los vigilantes y los filósofos. Hay una correlación estrecha entre estas clases y las facultades del alma humana, y, por tanto, a cada uno de estos grupos sociales pertenece de modo eminente una de las virtudes" (Marías, 1999, p. 53). El Estado y la sociedad son un organismo del mismo tipo que el hombre individual. El ciudadano se ejercita en la virtud que le corresponde, de la que está mejor dotados y de este modo satisfacen las necesidades de la sociedad. Desde tales consideraciones plantea que "una ciudad será justa y hará felices a los ciudadanos, si cada uno posee la virtud que corresponde a sus habilidades" (Gajate, 1999, p. 16).

La concepción orgánica del Estado de Platón es una organización tripartita, donde cada clase social está orientada por naturaleza por un tipo de alma, según Gajate (1999), para Platón, "en los artesanos domina el alma concupiscible, en los guerreros domina el alma irascible y en los gobernantes domina el alma racional" (p. 15). De este modo los ciudadanos cumplen la actividad que les corresponde por naturaleza para la que están mejor dotados y de este modo satisfacen las necesidades de la sociedad. Dependiendo de las aptitudes dominantes que tengan los ciudadanos, se organizaran en tres clases sociales.

El primer estamento es el de los gobernantes-filósofos, los únicos capaces para gobernar la sociedad y conocer la tarea moral del Estado, por ello su virtud es la prudencia. Por tanto, los únicos capaces de educación, por su areté o virtud particular. El segundo estamento es el de los guardianes-guerreros que tienen como misión la vigilancia y defensa de la ciudad, se añaden a la dirección del Estado como guardianes, es por ello que su virtud es la fortaleza; finalmente, el último estamento corresponde a los artesanos-productores que ofrecen los recursos necesarios para satisfacer las necesidades económicas de la polis, juegan un papel decisivo y están sometidos a las dos clases superiores a las que tienen que sostener económicamente (Albornoz, 2004, p. 105-106).

Pero estos tres estamentos o clases sociales sólo convivirán pacíficamente, dentro de la diversidad de sus intereses, si en el Estado reina la justicia. Esta división de las tareas no afecta al principio de justicia, más bien lo realiza y confirma, puesto, según Platón, la división de las funciones sociales no se funda en la herencia social, sino en dotes naturales. Desde la concepción orgánica de Estado de Platón la educación juega un papel determinante, en cuanto es medio para realizar la justica. Para evitar la decadencia propone la educación cuidadosa de la juventud de los estamentos superiores, seleccionando de entre ellos a los mejores, además, se aniquilarán a los infantes física y psíquicamente anormales, no cree en la educación para los ciudadanos con necesidades especial.

Los sabios han de vigilar el sistema educativo de modo que no se introduzcan cambios en él. Para evitar la decadencia el Estado educará cuidadosamente a la juventud de las clases superiores para que reciban una formación a fondo en la filosofía, a fin que alcanzando el 
conocimiento de lo bello y lo justo puedan acercarse al gobierno ideal. Es por ello que la educación, como expresión del Estado y la sociedad en Platón, está basada en la diferenciación de clases sociales, que surge de los caracteres y talentos de los individuos.

Para Platón lo decisivo en la vida del Estado es sobre todo la educación, más que las leyes o la forma de gobierno. Esto es así en cuanto que la clase dirigente, raza pura (gobernantesfilósofos) conservan y vigilan los principios de la educación, sobre los cuales se han fundado las leyes fundamentales del Estado. Es así: "que el mando esté en manos de uno sólo o de muchos, esto no altera en nada las leyes fundamentales del Estado, si los principios de la educación que hemos establecido son rigurosamente observados" (La República, Libro IV).

La consideración de la sociedad clasista de platónica se funda en la educación. La justicia llegará a la polis y acabaran todos sus males cuando llegue el poder de la raza pura (gobernantesfilósofos), donde éstos son los únicos capaces de establecer las normas (Leyes) de las relaciones humanas, es decir, el destino del Estado se somete a una dirección inteligente y objeto de estudio racional: "el mantenimiento de las instituciones y el orden establecido constituyen pues el objeto de los gobernantes" (Giménez, s/f). De este modo el Estado Ideal de justicia de Platón toma cuerpo en la realidad de las leyes establecidas por la clase sabia y dirigente. La clase superior tiene la tarea de la defensa del Estado, quienes a través de la aplicación de las leyes mantienen el orden y la armonía de la polis. En síntesis, el planteamiento sociopolítico de Platón se resume en la formación del hombre moral, dentro de un Estado estratificado, en cuanto éste representa la garantía de la justicia, por el cabal cumplimiento de la virtud que le es propia y corresponde por naturaleza.

\section{(6) Aristóteles, la educación como función del Estado:}

Para El Estagirita la educación es una función del Estado, pero necesaria para éste. El Estado aristotélico, no es el estratificado de Platón, sino el real, que es el fruto de la asociación libre de los hombres donde éstos cumplen de manera natural los fines acordes a su naturaleza. El ser humano es un ser político llamado a vivir en sociedad y el cual no forma parte de ninguna clase o grupo social superior. El Estado es el producto de la naturaleza animal y social del hombre que está ordenado esencialmente al individuo. El individuo logra alcanzar su destino moral en el Estado, gracias a la educación (Gajate, 2002, p. 22-24).

Desde la concepción del Estado Aristotélico, donde los gobernantes como los ciudadanos se someten por igual a las leyes, donde, además, los miembros de la polis tienen el mismo derecho de participar por igual en los negocios públicos y desempeñarse por igual en puestos de gobierno, el Estagirita concibe que la misión del última del Estado es la educación moral de los ciudadanos, ya que éstos son avaros y cobardes y como seres libres no observan las leyes impuestas por el éste. La preocupación de este tipo de Estado aristotélico es la plena realización de sus intereses logrando por medio de la educación, el desarrollo moral y la capacitación intelectual para desenvolverse en la polis. Por tanto, la educación adquiere una dimensión pública porque debe ser para todos, ordenada al bien moral de los ciudadanos, según Luzuriaga (1959) es "la plenitud de la realización humana en el hombre" (p. 66).

El Estado nace como una empresa ética que busca la realización moral del hombre. El Estado coloca a los ciudadanos en las mejores condiciones para que desarrollen sus 
potencialidades a través de la educación. Es así que, para Aristóteles, en una sociedad de iguales, la vida política se convierte en vida moral y la vida la moral en vida política gracias a la educación, ésta la más plena y dichosa realización a la que pueden acceder todos los ciudadanos de la polis para "vivir bien y rectamente según la virtud" (Bermúdez, 2011, p. 33).

\section{Consideraciones Finales}

Los planteamientos sociopolíticos de la educación, desarrollados en el pensamiento de la Grecia Clásica, en especial en las teorías de Sócrates, Platón y Aristóteles, se enmarcan en los principales interrogantes de orden antropológico, filosófico y ético desarrollados por ésta triada de filósofos. Le asignaron a la educación la tarea última de la existencia de la comunidad y de la individualidad humana, en cuanto que los ciudadanos de la polis se comprometían con los más sagrados intereses consagrados en las Leyes del Estado.

Como se ha señalado de los planteamientos antropológicos y éticos se derivaron los principios sociopolíticos de la educación griega. La educación debía formar al "hombre griego", al hombre libre, el cual, tenía que vivir según la virtud o areté que le es propia por naturaleza, concibiéndose responsablemente como individuo y ciudadanos. Hombres libres y políticos, en cuanto ciudadanos, que viven en la polís, la ciudad, centro de la cultura. Educando para el desarrollo humano y la convivencia social y política, en un contexto de transformación radical de la Atenas del siglo $\mathrm{V}$ a.C. que exigía una nueva clase social incorporada a una democracia más extensa y de una Grecia que se vislumbra como mueva potencia de dominación imperial.

La educación griega es eminentemente política y encuentra su razón de ser en el carácter humano y cívico. La educación política deriva de la antropología y se realiza en la vida ética que se vierte en vida política. Por ello, la preocupación del Estado Griego era la educación del hombre integral: física, intelectual, ética y estéticamente. De los planteamientos educativos se produce la síntesis entre educación y cultura, dando así un valor agregado al arte, a la literatura, a las ciencias, a la moral y a la filosofía. La riqueza de los postulados sociopolíticos de la educación griega encuentra su fecundidad en su valor humanístico. Claro está, que tales planeamientos varían en razón de la concepción de hombre sobre la que se propone una visión de Estado y sociedad, de la cual la educación es garantía. En el caso de Sócrates el fin social de la educación, en cuanto que el hombre es un ser teleológicamente orientado a la virtud, está en la formación moral y ética del ciudadano. La excelencia de la moral es la máxima del hombre, no el aprovechamiento personal, ni la indiferencia ante la objetividad y la eticidad, tal como sucedía en la educación Sofista, con la cual coincidía por el valor que otorgaban al hombre como centro de la educación.

En el caso de Platón, que sigue de cerca a su maestro, predominan las ideas éticas, la preocupación por la justicia. El fin político de la educación es la formación del hombre de las clases dirigentes, los filósofos-gobernantes, los cuales por medio de la educación moral de su estamento social son la única garantía de la pervivencia del Estado, en cuanto en ellos por la educación, en razón de su naturaleza (virtud o areté) superior encarnan la idea de justicia. Es por ello que la educación, como expresión del Estado y la sociedad en Platón, está basada en la diferenciación de clases sociales, que surge de los caracteres y talentos de los individuos. 
En cambio, en Aristóteles, la educación descansa en una visión positiva de la naturaleza humana, por considerar al hombre un animal social-político. El ser humano es un ser político llamado a vivir en sociedad y el cual no forma parte de ninguna clase o grupo social superior. Es por ello, que el Estado que nace como una empresa ética, busca la realización moral del hombre, elevándolo a la calidad ciudadano en las mejores condiciones para que desarrollen sus potencialidades a través de la educación: desarrollo moral y capacitación intelectual para desenvolverse en la polis.

\section{Bibliografía}

Albornoz, J. (2004). Nociones elementales de filosofía. Valencia-Caracas, Venezuela: Vadell Hermanos.

Barrera, F. (2000). Sugerencias para redactores, comunicadores e investigadores. Caracas: SYPAL

Bermúdez, J. (2011). La felicidad desde la ética a Nicómaco de Aristóteles. Trabajo de grado no publicado, Universidad Católica Cecilio Acosta, Maracaibo.

Fischl, J. (2002). Manual de Historia de la Filosofía. Barcelona-España: Herder

Gadotti, M. (2004). Historia de las ideas pedagógicas. Buenos Aires, Argentina: Siglo Veintiuno

Gajate, J. (1999). Los Sofistas y Sócrates. Bogotá, Colombia: El Buho.

Gajate, J. (1999). Platón. Teoría de las ideas. Bogotá, Colombia: El Buho.

Gajate, J. (2002). Aristóteles. Metafísica, Ética y Política. Bogotá, Colombia: El Buho.

Giménez, F. (s/f). Lecciones sobre Aristóteles. [Documento en Línea] Obtenido de: http://www.filosofia.net/materiales/tem/aristote.thm. [Consulta. 2011 Mayo 08].

Larroyo, F. (1991). Platón. Las Leyes, Epinomis y el Político. México: Porrua

Luzuriaga, L. (1959). Historia de la educación y de la pedagogía. Buenos Aires, Argentina: Losada

Marías, J. (1999). Historia de la filosofía. Madrid, España: Alianza

Rentería, P. (2004). Formación de docentes. Un reto para las escuelas normales superiores y las facultades de educación. Bogotá, Colombia: Magisterio

Rodríguez, L. (2006). Ética. Madrid, España: Biblioteca de Autores Cristianos.

Universidad Pedagógica Experimental Libertador (1999). Introducción a la filosofía. Caracas, Venezuela: Talleres de Encuadernación Dulia C.A.,

Universidad Pedagógica Experimental Libertador (2006). Manual de Trabajos de Grado de Especialización y Maestrías y Tesis Doctorales. Caracas-Venezuela: Vicerrectorado de Investigación y Postgrado. 